\title{
LAMC2 enhances the metastatic potential of lung adenocarcinoma
}

\author{
YW Moon ${ }^{1,2}$, G Rao ${ }^{3}$, JJ Kim ${ }^{4,9}$, H-S Shim ${ }^{5,9}$, K-S Park, ${ }^{1,3}$, SS An ${ }^{6}$, B Kim ${ }^{7,10}$, PS Steeg ${ }^{8}$, S Sarfaraz ${ }^{1}$, L Changwoo Lee ${ }^{1}$, Donna Voeller ${ }^{1}$, \\ EY Choi ${ }^{6}$, Ji Luo ${ }^{1}$, D Palmieri ${ }^{8}$, HC Chung ${ }^{2}$, J-H Kim², Y Wang ${ }^{*, 1,3}$ and G Giaccone ${ }^{*, 1,3}$
}

Lung cancer is the number one cancer killer, and metastasis is the main cause of high mortality in lung cancer patients. However, mechanisms underlying the development of lung cancer metastasis remain unknown. Using genome-wide transcriptional analysis in an experimental metastasis model, we identified laminin $\gamma 2$ (LAMC2), an epithelial basement membrane protein, to be significantly upregulated in lung adenocarcinoma metastatic cells. Elevated LAMC2 increased traction force, migration, and invasion of lung adenocarcinoma cells accompanied by the induction of epithelial-mesenchymal transition (EMT). LAMC2 knockdown decreased traction force, migration, and invasion accompanied by EMT reduction in vitro, and attenuated metastasis in mice. LAMC2 promoted migration and invasion via EMT that was integrin $\beta 1$ - and ZEB1-dependent. High LAMC2 was significantly correlated with the mesenchymal marker vimentin expression in lung adenocarcinomas, and with higher risk of recurrence or death in patients with lung adenocarcinoma. We suggest that LAMC2 promotes metastasis in lung adenocarcinoma via EMT and may be a potential therapeutic target.

Cell Death and Differentiation (2015) 22, 1341-1352; doi:10.1038/cdd.2014.228; published online 16 January 2015

Lung cancer is the leading cause of cancer-related death. ${ }^{1}$ Non-small-cell lung cancer (NSCLC) accounts for $~ 80-85 \%$ of lung cancers. ${ }^{2}$ Only $20-30 \%$ of NSCLC are radically resectable and the majority of lung cancer patients succumb to the disease. The high mortality of NSCLC is largely attributable to late diagnosis, when metastases are present. ${ }^{2}$ The molecular mechanisms governing metastasis of NSCLC remain poorly understood.

Metastasis is a complex, multistep process, involving migration and invasion of malignant cells from the primary tumor to blood vessels, intravasation, and survival in the circulation, and ultimately extravasation, colonization, and formation of secondary tumor at distant target organs. ${ }^{3}$ Each of these events is classically driven by the acquisition of genetic and/or epigenetic traits in tumor cells and the cooperation of nonneoplastic stromal cells. Increased or decreased expression of several genes in tumors has been found to be correlated with metastasis. ${ }^{3}$ However, specific gene alterations that drive NSCLC metastasis remain largely elusive.

Laminin $\gamma 2$ (LAMC2) is a subunit of the heterotrimeric glycoprotein laminin-332 (LAM-332, formerly laminin-5), consisting of the $a 3, \beta 3$, and $\gamma 2$ chains. Although LAMC2 is an important structural component of the epithelial basement membrane (BM) in various normal tissues, ${ }^{4}$ there is an emerging evidence for a pathological role of LAMC2 monomer in cancer. It has been demonstrated that LAMC2 protein expression correlates with clinical outcome of stage I lung adenocarcinoma (ADC) patients. ${ }^{5,6}$ In addition, noncontinuous expression pattern of LAMC2 predicts the prognosis of esophageal squamous cell carcinoma (SCC), ${ }^{7}$ and secreted LAMC2 in the serum is associated with the aggressiveness of pancreatic cancer. ${ }^{8}$ Besides, LAMC2 monomer expression has been frequently found in the invasive front of epithelial tumors such as ADCs of the stomach, colon, pancreas, and lung, SCCs of the esophagus, head and neck, skin and lung, and transitional cell carcinoma of the bladder. ${ }^{5,9-14}$ Epithelialmesenchymal transition (EMT) has a critical role in the early stages of dissemination of malignant epithelial tumors leading to metastatic spread. ${ }^{15}$ There is growing evidence that LAMC2 expression increases in the carcinoma cells undergoing EMT, ${ }^{16-18}$ and that level of LAMC2 expression is regulated directly by the EMT master regulator ZEB1 and activated $\beta$-catenin in invasive colorectal carcinoma cells. ${ }^{19,20}$

Combining results of gene expression microarrays with a metastasis selection model in mice, we found a robust

\footnotetext{
${ }^{1}$ Medical Oncology Branch, National Cancer Institute, National Institutes of Health, Bethesda, MD 20892, USA; ${ }^{2}$ Division of Medical Oncology, Yonsei Cancer Center, Yonsei University College of Medicine, Seoul, South Korea; ${ }^{3}$ Lombardi Comprehensive Cancer Center, Georgetown University, Washington, DC, USA; ${ }^{4}$ Department of Bioengineering, Johns Hopkins University, Baltimore, MD, USA; ${ }^{5}$ Department of Pathology, Yonsei University College of Medicine, Seoul, South Korea; ${ }^{6}$ Department of Environmental Health Sciences, Johns Hopkins University, Bloomberg School of Public Health, Baltimore, MD, USA; ${ }^{P}$ Pathology Branch, National Cancer Institute, National Institutes of Health, MD, USA and ${ }^{8}$ Women's Cancers Section, Laboratory of Molecular Pharmacology, National Cancer Institute, National Institutes of Health, Bethesda, MD, USA

${ }^{*}$ Corresponding author: Y Wang or G Giaccone, Lombardi Comprehensive Cancer Center, Georgetown University, 3970 Reservoir Road NW, Washington, DC, USA. Tel: +1 2026874738 (YW) or +1 2026877072 (GG); Fax: +1 202687 0313; E-mail: yw350@ georgetown.edu (YW) or gg496@ georgetown.edu (GG)

${ }^{9}$ These authors contributed equally to this work.

${ }^{10}$ Current address: Hamllym University Kangdong Sacred Heart Hospital, Gandong-Gu, Seoul, Korea

Abbreviations: LAMC2, laminin $\gamma 2$; EMT, epithelial-mesenchymal transition; NSCLC, non-small-cell lung cancer; ADC, adenocarcinoma; SCC, squamous cell carcinoma; BM, basement membrane; qRT-PCR, quantitative reverse transcription-polymerase chain reaction; ECM, extracellular matrix; shRNA, small hairpin RNA; TMA, tissue microarray; IHC, immunohistochemistry; LUC, luciferase

Received 09.7.14; revised 18.11.14; accepted 28.11.14; Edited by R De Maria; published online 16.1.15
} 
association between metastatic derivatives of A549 lung ADC cells and increased expression of LAMC2. Here we demonstrate that LAMC2 promotes migration, invasion and metastasis in human lung ADC cells via induction of EMT. Furthermore, LAMC2 expression is prognostic in resected $A D C$ of the lung and a potential therapeutic target.

\section{Results}

LAMC2 is a metastatic marker in lung ADC. Intracardiac and tail vein injections of human tumor cells into immunocompromised mice are two well-established systems to study tumor metastasis in vivo. To evaluate metastasis potential of NSCLC cells, we chose intracardiac injection model in which cells may metastasize throughout the body, instead of tail veil injection model in which cells preferentially metastasize to the lung. Briefly, we used a nude mouse metastasis model of repeated intracardiac injections of A549 ADC cells derived and cultured from tumor cells metastatic to the brain (Figure 1a). After three rounds of in vitro culture and in vivo brain metastatic selection, $100 \%$ brain metastasis penetrance was obtained (10 out of 10 mice). To verify the potential brain tropism of the metastatic cells established in this model, bioluminescent imaging was performed after intracardiac injection of A549 round 3 (A549R3)-Brain cells transfected with firefly luciferase expression vector. Bioluminescent imaging demonstrated that A549R3-Brain cells metastasized to various other organs, in addition to the brain (Figure 1b). Subsequently, A549R4 cells were established by culturing metastatic cells derived from various organs (see below) after injection of A549R3-Brain cells (Figure 1b).

To identify genes that may be involved in metastasis, we compared mRNA expression profiles between A549 round 0 (A549R0) and A549R3 cells by microarray analysis. Expression profiles of A549 (our data) and PC9 metastatic cells (public data, GSE14107), ${ }^{21}$ which were independently derived using the same mouse metastasis model, revealed 48 differentially expressed genes that were common in both systems, with criteria of false discovery rate $<0.1$ and $\log 2$ fold change $>1.5$ or $<-1.5$ (Figure $1 \mathrm{c}$ and Supplementary Figure S1A, and Supplementary Table S1). Differentially expressed genes were further narrowed down to 11 based on unidirectional log 2 fold change across R1, R2, and R3, and on only genes reported to have cancer-associated function. Our microarray data demonstrated that LAMC2 was the most significantly induced gene in metastatic A549 cells and highly induced in metastatic PC9 cells, although not the most highly expressed (Figure 1c). Real-time quantitative reverse transcription-polymerase chain reaction (qRT-PCR) and immunoblot assays confirmed that LAMC2 was upregulated in A549R3 and A549R4, compared with A549R0 cells (Figures 1d and e).

Among the 11 differentially expressed metastasisassociated genes (Figure 1c), we confirmed the results of RNA microarrays in 8 by real-time qRT-PCR and/or immunoblot assays in metastatic series of A549 cells derived from brain, femur, and spine metastases. Particularly evident was the upregulation of LAMC2 (Figures 1d and e) and AXL (data not shown) in A549R3 and A549R4, compared with A549R0 cells. The receptor tyrosine kinase AXL is an oncogene shown to promote tumor cell growth, metastasis, and drug resistance to HER2 and epithelial growth factor receptor-targeted therapy. ${ }^{22-25}$ LAMC2 expression has been shown to be associated with prognosis in several solid tumors, ${ }^{5,9-14}$ but its role in the metastatic process is not clear.

LAMC2 promotes migration, invasion, and traction of lung ADC cells in concomitance with EMT. Given the implications of LAMC2 as a marker of tumor invasiveness, ${ }^{5,9-14}$ our finding prompted us to study the potential involvement of LAMC2 in lung ADC metastasis. We observed that progressive upregulation of LAMC2 expression from A549R0 to A549R4 cells was significantly associated with increased capacity to migrate and invade Matrigels in vitro (all $P$-values $<0.05$; Figure $2 a$ ), with the only exception of the comparison between R3-Brain and R4-Brain cells $(P>0.05)$. LAMC2 expression levels, however, had no impact on cell doubling time (Figure $2 b$ ).

To further explore the role of LAMC2 in lung ADC metastasis, we ectopically expressed LAMC2 in four lung ADC cell lines (A549R0, PC9, H838, and H2122) with low to intermediate levels of endogenous LAMC2 expression. Compared with mock controls, stably LAMC2-transfected cells exhibited marked increases in migration and invasion $(P<0.05$ across all cell lines; Figure $2 c)$. Conversely, LAMC2shRNA (LAMC2-short hairpin RNA) knockdown significantly reduced migration and invasion capacities of lung ADC cell lines (A549R4, PC9, H358, and H322) compared with their respective control shRNA-transfected cells (all $P<0.05$; Figure 2d). Ectopic LAMC2 expression or knockdown did not affect cell proliferation (all $P>0.05$; Supplementary Figure S2A). Migrating cells exert traction force upon their surroundings, ${ }^{26,27}$ and cell traction force is necessary in cancer cell migration and invasion. ${ }^{28,29}$ Fourier transform traction microscopy showed that stably LAMC2-transfected A549R0 cells were bigger in size $(P<0.05)$ and exhibited greater cell traction force (Figure $2 \mathrm{e}$ ), with $\sim 1.5$-fold higher $(P<0.05)$ net contractile moment compared with mock control. Similar results were observed in A549R3-Brain and A549R4-Femur cells as compared with A549R0 cells (Supplementary Figure S2B). In contrast, LAMC2-shRNA knockdown in H358 cells (Figure 2f) and PC9 cells (Supplementary Figure S2C) resulted in marked decreases in cell size and traction force. Consistently, H358-shLAMC2 and PC9-shLAMC2 cells attached to the surface more slowly than their corresponding control cells (all $P$-values $<0.05$; Supplementary Figures S2D and E). These findings provide direct evidence that LAMC2 may positively regulate migration, invasion, traction, and attachment of lung ADC cells.

Epithelial-mesenchymal transition (EMT) has been linked to the early stages of dissemination of malignant epithelial tumors leading to metastatic spread. ${ }^{15} \mathrm{We}$ examined the expression of EMT master regulators ZEB1 or Snail. ${ }^{15}$ Immunoblots showed that ZEB1 and/or Snail expression increased in the LAMC2-transfected cells but decreased in the LAMC2-knockdown cells compared with their corresponding control cells (Figure 2g). Other EMT regulators such as ZEB2, Slug, or Twist were not altered (data not shown). E-cadherin, an epithelial marker, 

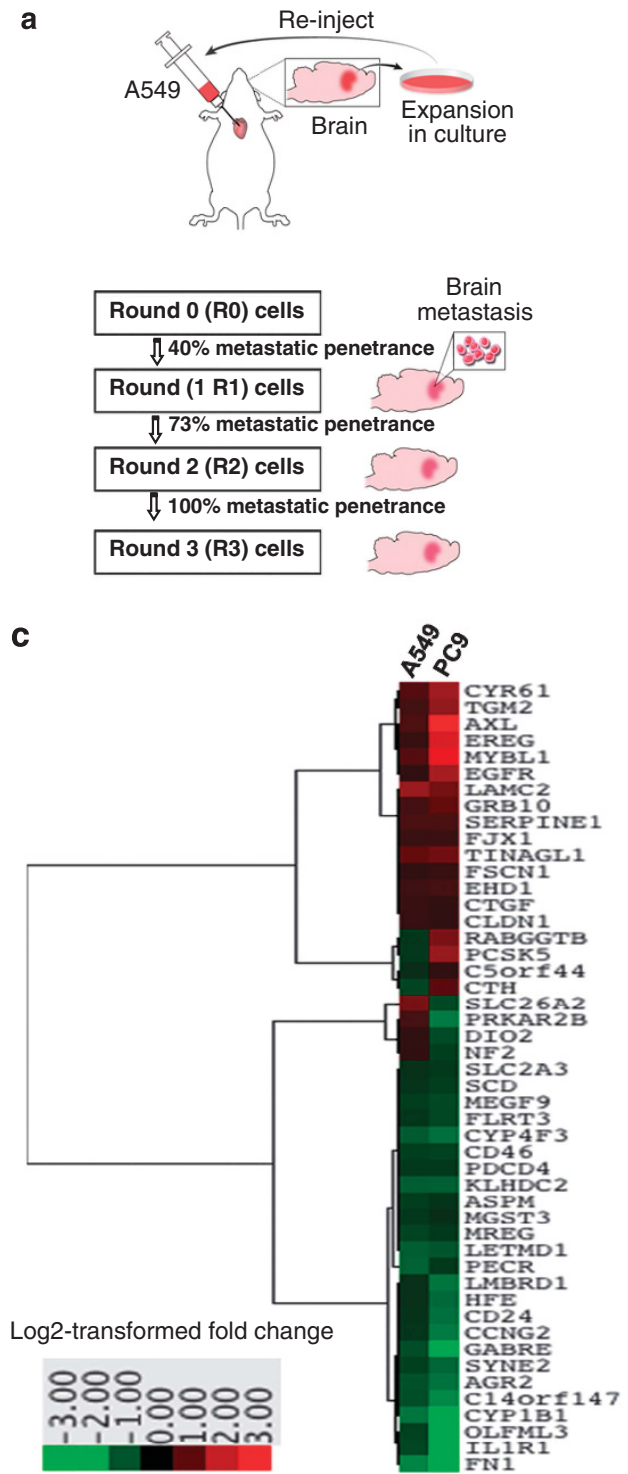

d

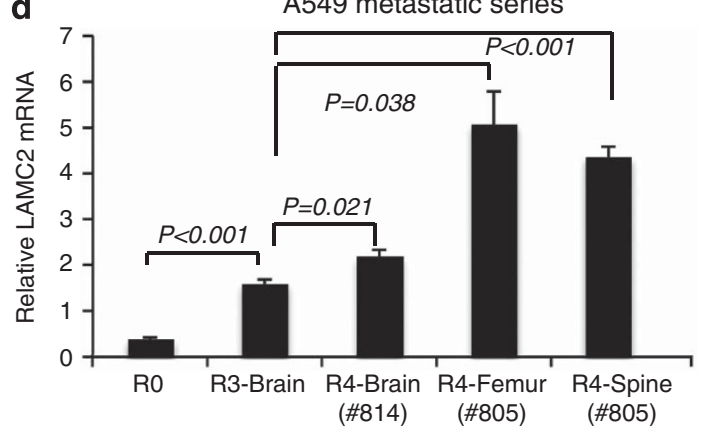

b
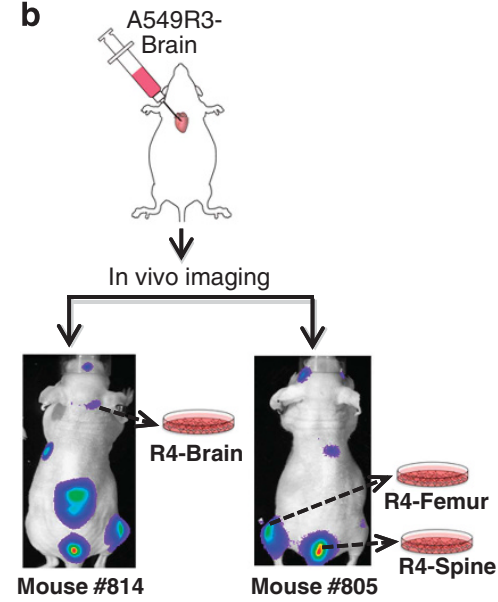

\begin{tabular}{lcc}
\multicolumn{3}{c}{$\begin{array}{c}\text { Selected metastasis- } \\
\text { associated genes }\end{array}$} \\
\hline & $\begin{array}{c}\text { A549 } \\
\text { (our data) }\end{array}$ & $\begin{array}{c}\text { PC9 } \\
\text { (public data) }\end{array}$ \\
\cline { 2 - 3 } Gene & $\begin{array}{c}\text { Fold } \\
\text { change }\end{array}$ & $\begin{array}{c}\text { Fold } \\
\text { change }\end{array}$ \\
Symbol & 2ha & 2.32 \\
LAMC2 & 2.91 & 14.5 \\
AXL & 1.81 & 5.38 \\
MYBL1 & 1.88 & 3.06 \\
CYR61 & 1.89 & 1.53 \\
CTGF & 1.57 & 2.79 \\
TGM2 & 1.69 & 1.58 \\
FSCN1 & 1.51 & -1.6 \\
ASPM & -1.71 & -2.71 \\
CCNG2 & -1.62 & -1.65 \\
PDCD4 & -1.64 & -2.48 \\
CD24 & -1.57 &
\end{tabular}

e $\quad$ A549 metastatic series

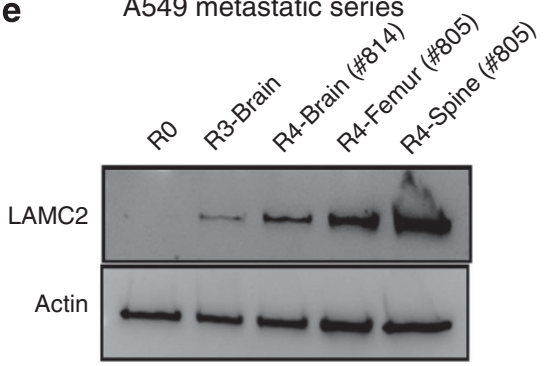

Figure 1 Identification of LAMC2 as a putative metastasis marker of NSCLC. (a) A schematic illustration of the in vivo mouse metastasis model with repeated intracardiac injections of A549 cells. Outgrowth of A549 cells from the cultured brain tissue indicated that injected A549 cells metastasized to the brain. A549R1, A549R2, and A549R3 cells were serially established by performing intracardiac injection of A549R0 $\left(5 \times 10^{5}\right.$ cells), A549R1 (2.5 $\times 10^{5}$ cells), and A549R2 $\left(2.5 \times 10^{5}\right.$ cells), respectively. For each round, 10 mice were injected. (b) Bioluminescent images after intracardiac injection of luciferase-transfected A549R3-Brain cells, demonstrating non-brain tropism. A549R4-Brain, -Femur, and -Spine cells were established after culturing metastatic cells derived from the corresponding organ metastases after injection of A549R3 cells. (c) Expression profiles of A549 (our data) and PC9 metastatic cells (public data, GSE14107), which were independently derived using the intracardiac injection mouse metastasis model, revealed 48 differentially expressed genes between R0 and R3 that were common in both systems, with criteria of false discovery rate $<1.0$ and log 2 fold change $>1.5$ or $<-1.5$. Differentially expressed genes were further narrowed down to 11 based on the unidirectional log 2 fold change across R1, R2, and R3, and including only genes reported to have cancer-associated function. (d) Real-time qRT-PCR analysis of LAMC2 in A549R0, A549R3, and A549R4 cells. Student's t-test was performed to compare A549R0 versus A549R3 and A549R3 versus A549R4. Data are presented as mean \pm S.E.M. of triplicate experiments. (e) Immunoblot analysis of LAMC2 in A549R0, A549R3, and A549R4 cells 
increased in A549R4-Femur-shLAMC2, H358-shLAMC2, and H322-shLAMC2 cells, whereas the mesenchymal markers $\mathrm{N}$-cadherin and/or vimentin increased in the
A549R0-LAMC2 cells but decreased in the A549R4-FemurshLAMC2, H358-shLAMC2, and H322-shLAMC2 cells (Figure 2g). H358-shLAMC2 (shRNA no. 1) knockdown
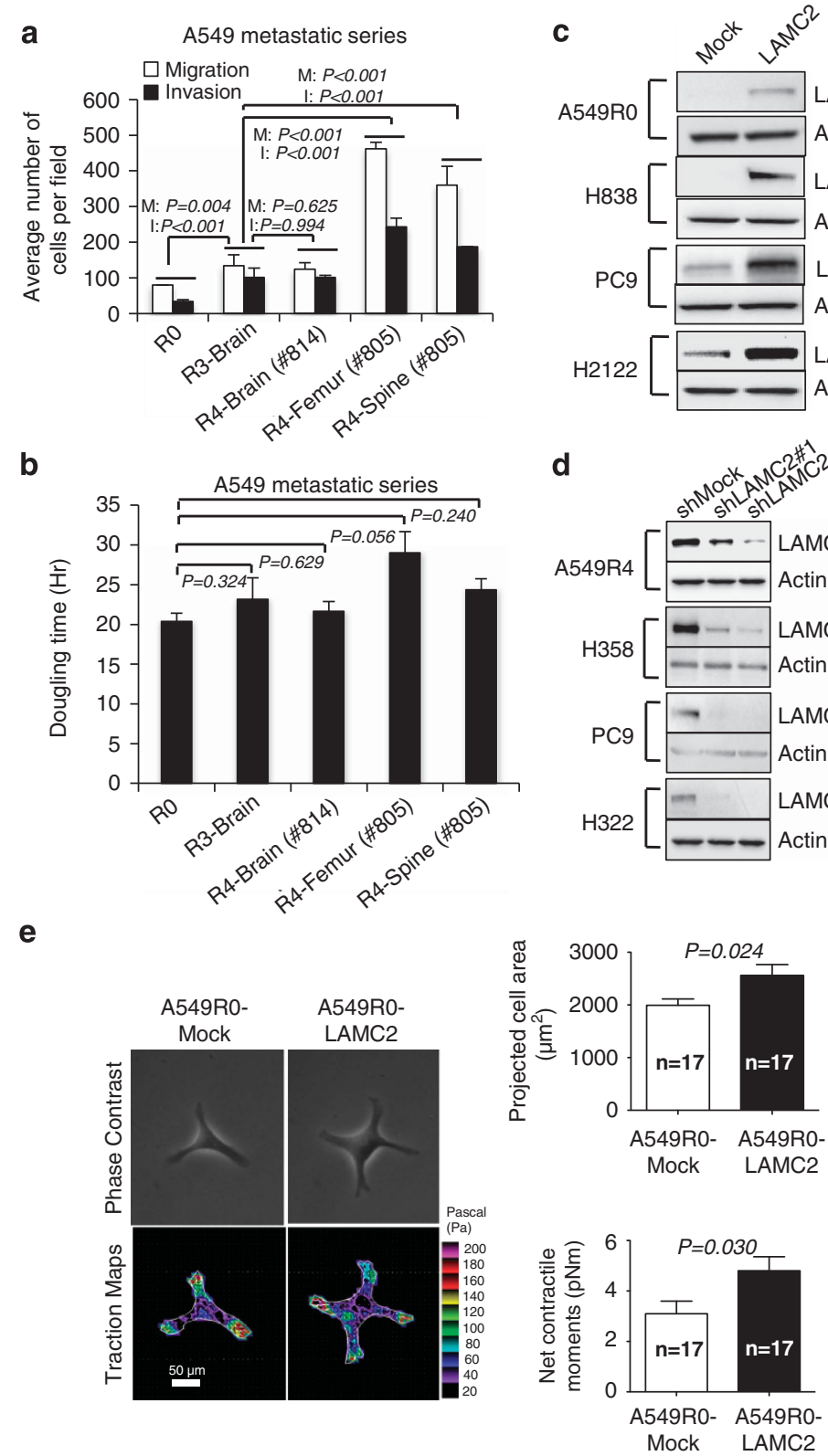

b

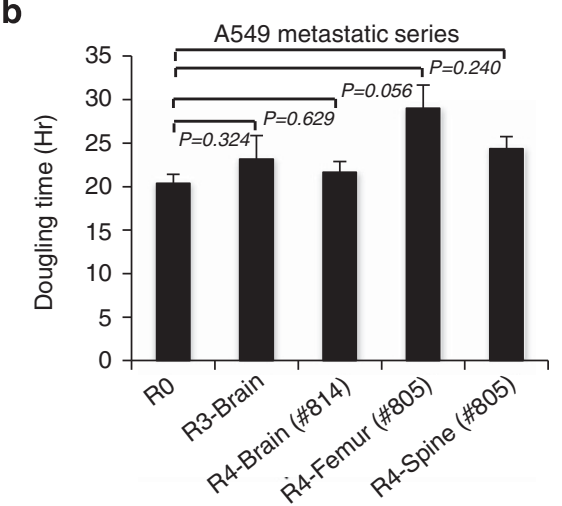

\section{。}

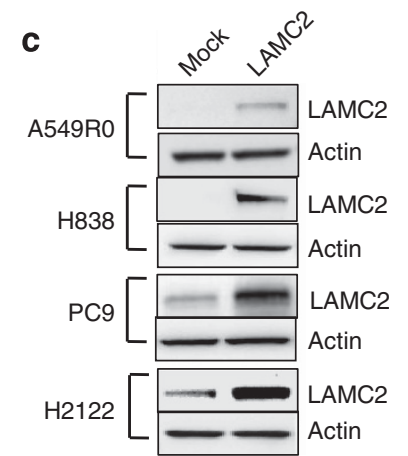

d

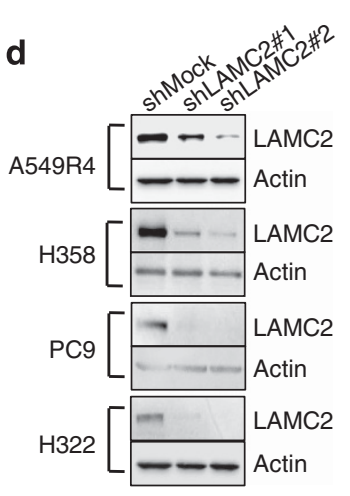

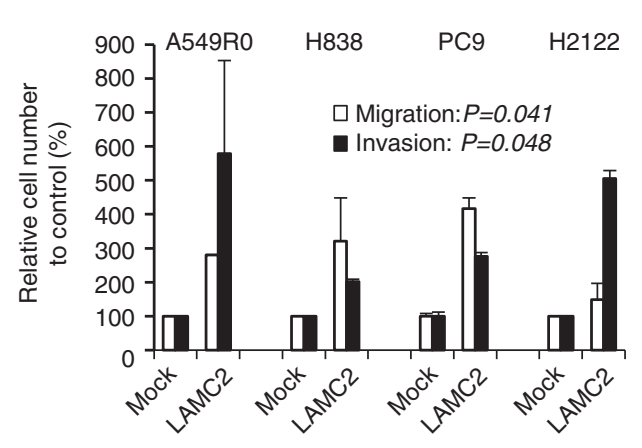

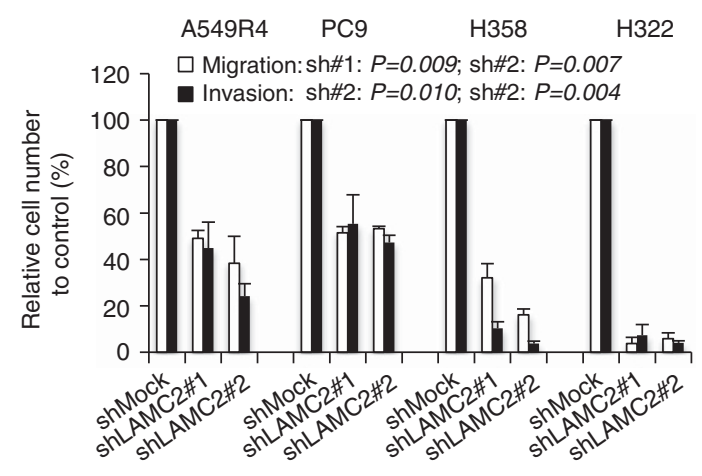

f

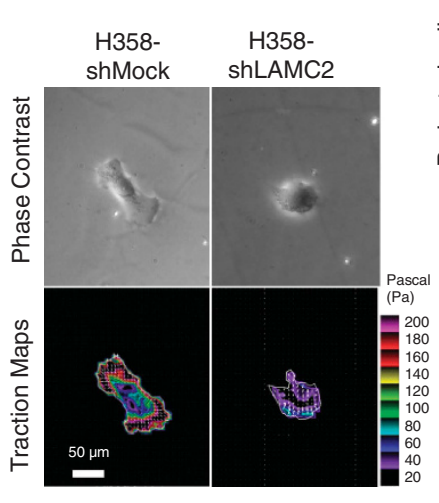

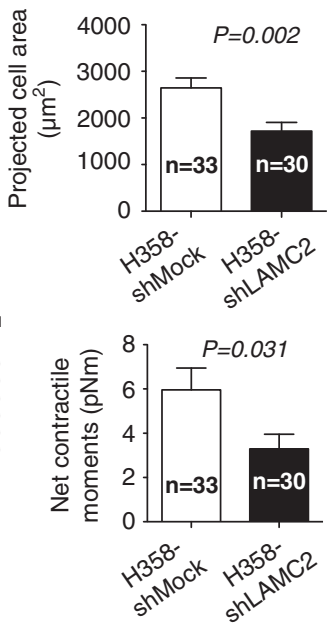


cells showed similar pattern of EMT marker change to H358-shLAMC2 (shRNA no. 2) (data not shown), suggesting that the changes observed in EMT markers were not off-target effects of LAMC2 knockdown. These data suggest that LAMC2 may regulate NSCLC migration and invasion through the modulation of EMT.

Secreted LAMC2 enhances cell migration and invasion. LAM-332 was reported to be a scatter or motility factor secreted by tumor cells or normal epithelial cells, inducing motility of gastric cancer, ${ }^{30}$ melanoma, ${ }^{31}$ and breast cancer cells. ${ }^{32}$ To determine whether LAMC2 was secreted by the lung ADC cells, cells were cultivated in RPMI-1640 without additives, serum, or other growth factors for $24 \mathrm{~h}$. The conditioned medium was then collected, followed by ultracentrifugal filter concentration (Supplementary Figure S3A). Immunoblot analysis using the concentrated conditioned medium identified secreted unprocessed $(140 \mathrm{kDa})$ and processed $(100 \mathrm{kDa})$ LAMC2 (Figure 3a), whereas the $100 \mathrm{kDa}$ LAMC2 was detected in the cell lysates at much lower level than in conditioned medium (data not shown). Our data are consistent with a previous study showing LAMC2 subunit is subjected to cleavage into a mature form upon extracellular secretion. ${ }^{33}$ To investigate whether secreted LAMC2 was a motility factor, conditioned medium was added to Boyden chamber inserts containing LAMC2-knockdown cells for the migration and invasion assays. Conditioned media derived from PC9-shLAMC2 or H358-shLAMC2 cells contained less secreted LAMC2 (Figure 3a) and induced less migration and invasion (all $P$-values $<0.05$; Figure $3 \mathrm{~b}$ and Supplementary Figure S3B) than those from PC9-shMock or H358-shMock cells. In addition, migration of LAMC2knockdown PC9 cells was enhanced by the concentrated conditioned medium in a dose-dependent manner (all $P$-values $<0.05$; Supplementary Figure S3C). Moreover, LAMC2-blocking antibody attenuated A549R0 cell migration and invasion induced by A549R0-LAMC2 cell conditioned medium (all $P$-values $<0.05$; Figure $3 \mathrm{c}$ ), suggesting that secreted LAMC2 enhances cell migration and invasion.

LAMC2 knockdown reduces metastasis in mice. To test the in vivo effects of LAMC2 on lung ADC metastasis, we evaluated the metastatic capacity of luciferase-transfected ADC cells in our intracardiac injection metastasis model. In vitro baseline bioluminescent intensities of luciferase-transfected A549R4-shLAMC2 and A549R4-shMock cells were similar or slightly stronger in A549R4-shLAMC2 cells (Supplementary Figure S4A). Luciferase-positive A549R4-shLAMC2 and
A549R4-shMock cells were intracardially injected into nude mice. Serial noninvasive bioluminescent imaging was performed weekly for 4 weeks and then biweekly for the next 2 weeks (Figure 4a). Selected bioluminescent hot spots acquired by in vivo bioluminescent images were confirmed to be metastatic tumors by histologic examination (Supplementary Figure S4B). From the first week on, knockdown of LAMC2 consistently reduced metastatic activity of A549R4 cells. At 6 weeks, the average number of metastases per mouse was 1.9-fold lower in A549R4-shLAMC2 cells than in A549R4-shMock cells $(4.1 \pm 2.1$ for LAMC2 knockdown versus $7.7 \pm 3.6$ for control; $P=0.017$; Figure $4 \mathrm{~b}$ ), indicating that LAMC2 knockdown attenuated metastasis.

LAMC2 promotes migration and invasion via integrin $\boldsymbol{\beta} 1$ - and/or ZEB1-dependent EMT. Previous work showed that LAMC2 binds to integrin $\alpha 2 / \beta 1,{ }^{34}$ and integrin is required for invasion in some tumors. ${ }^{35}$ To test whether integrin participates in LAMC2-induced EMT, we first assessed the potential interaction between LAMC2 and integrin in NSCLC cells. LAMC2 pulldown experiments showed that both endogenous and exogenous LAMC2 interacted with integrin $\beta 1$ in $\mathrm{H} 2122, \mathrm{PC} 9$, and A549R4 cells (Figure 5a). This was confirmed by the reciprocal integrin $\beta 1$ pulldown in the same cell lines (Figure 5b). LAMC2-positive cells secreted LAMC2, suggesting that the secreted LAMC2 may act in an autocrine loop where it binds to integrin $\beta 1$ receptor on the cell surface, which in turn induces EMT. To validate this hypothesis, we knocked down integrin $\beta 1$ in LAMC2-negative A549R0 cells treated either with A549R0 conditioned medium, which did not contain LAMC2, or with A549R4 conditioned medium, which was rich in secreted LAMC2. Depletion of integrin $\beta 1$ led to reduction of $\mathrm{N}$-cadherin expression concomitant with the induction of E-cadherin (Figure 5c), suggesting that integrin $\beta 1$ knockdown blocks LAMC2-induced EMT. The same finding was confirmed in LAMC2-positive A549R4 cells where depletion of integrin $\beta 1$ reversed the EMT signaling (Figure $5 \mathrm{~d}$ ). Moreover, integrin $\beta 1$ knockdown reduced migration and invasion of A549R0 and PC9 cells treated with A549R0 and A549R4 conditioned media (Figures 5e and f), suggesting that integrin $\beta 1$ may be a downstream effector of LAMC2-mediated EMT signaling.

The fact that blocking EMT by integrin $\beta 1$ knockdown attenuates LAMC2-mediated migration and invasion suggests that LAMC2 may promote NSCLC migration and invasion through the modulation of EMT. To validate this hypothesis, we investigated whether the impact of LAMC2 on cell migration and invasion is dependent on EMT master regulators ZEB1 and Snail. ZEB1-shRNA knockdown in A549R0-LAMC2 cells

Figure 2 LAMC2 promotes migration, invasion, and traction of lung ADC cells concomitantly with EMT induction. (a) Migration and invasion analysis of A549R0, A549R3, and A549R4 cells. Student's t-test was performed to compare A549R0 versus R3 and R3 versus R4. Data are mean \pm S.E.M. of triplicate experiments. (b) Doubling times of A549R0, R3, and R4 cells. $P$-values were calculated by paired $t$-test. Data are mean \pm S.E.M. of triplicate experiments. (c) Immunoblot analysis of LAMC2 and migration and invasion assays in LAMC2-transfected cells. Triplicates of migration and invasion assays were performed for each cell line. $P$-values were calculated by paired $t$-test between Mock and LAMC2 across four cell lines. (d) Immunoblot analysis of LAMC2 and migration and invasion assays in LAMC2-knockdown cells. Triplicates of migration and invasion assays were performed for each cell line. $P$-values were calculated across four cell lines by paired t-test between shMock- and shLAMC2 no.1-transfected cells or shMock- and shLAMC2 no. 2-transfected cells. (e and f) Representative images of phase-contrast and traction maps (left panels), projected cell area (right upper panels), and net contractile moments (right lower panels) in (e) A549R0-LAMC2 and Mock cells, and (f) H358-shLAMC2 and shMock cells. In traction maps, the white lines show the cell boundary, colors show the magnitude of the tractions in Pascal (Pa), and arrows show the direction and relative magnitude of the tractions. Scale bars: $50 \mu \mathrm{m}$. Student's $t$-test was used to compare groups; $n$ is the the number of cells analyzed. Data are presented as mean \pm S.E.M. $(\mathbf{g})$ Immunoblot of EMT-related proteins in LAMC2-transfected and -knockdown cells 
a

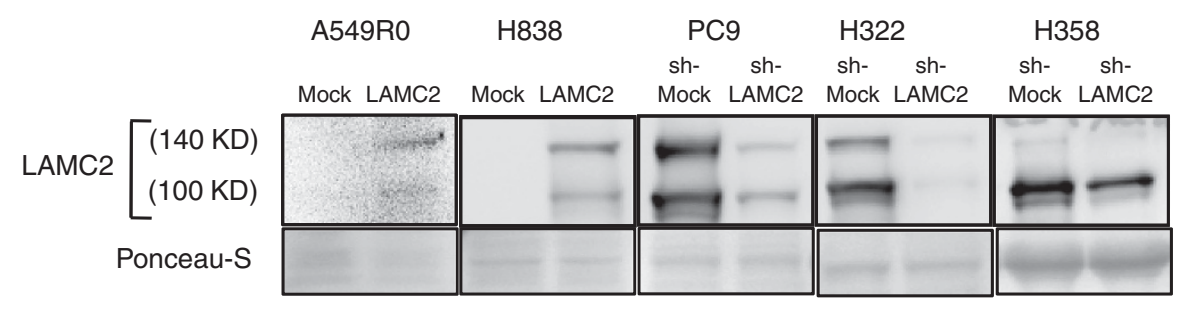

b
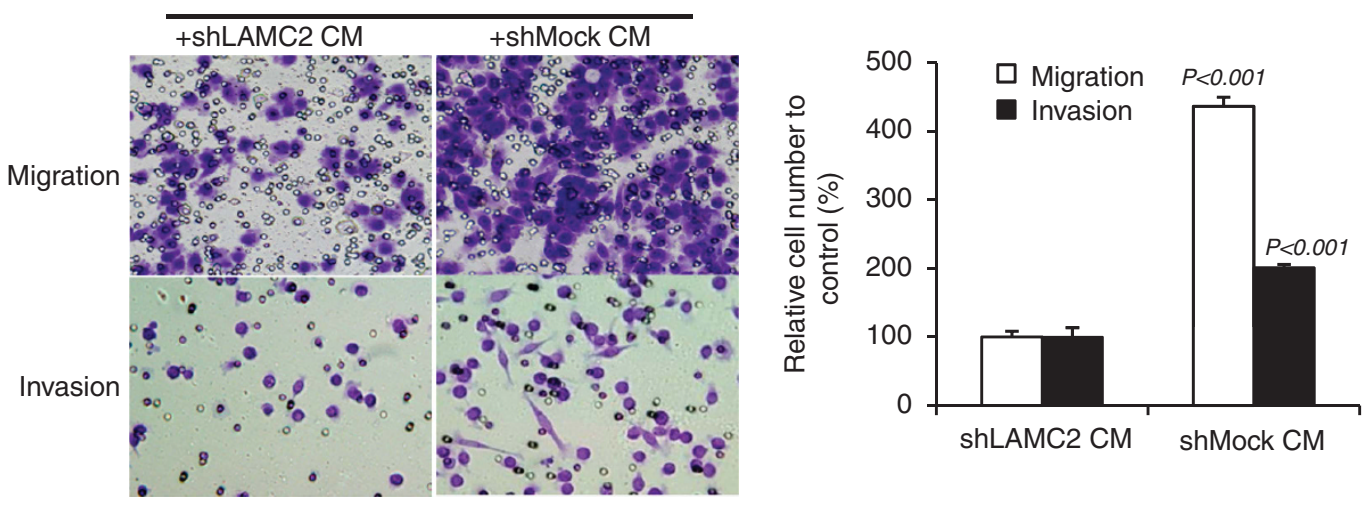

C

A549R0 + CM enriched in LAMC2
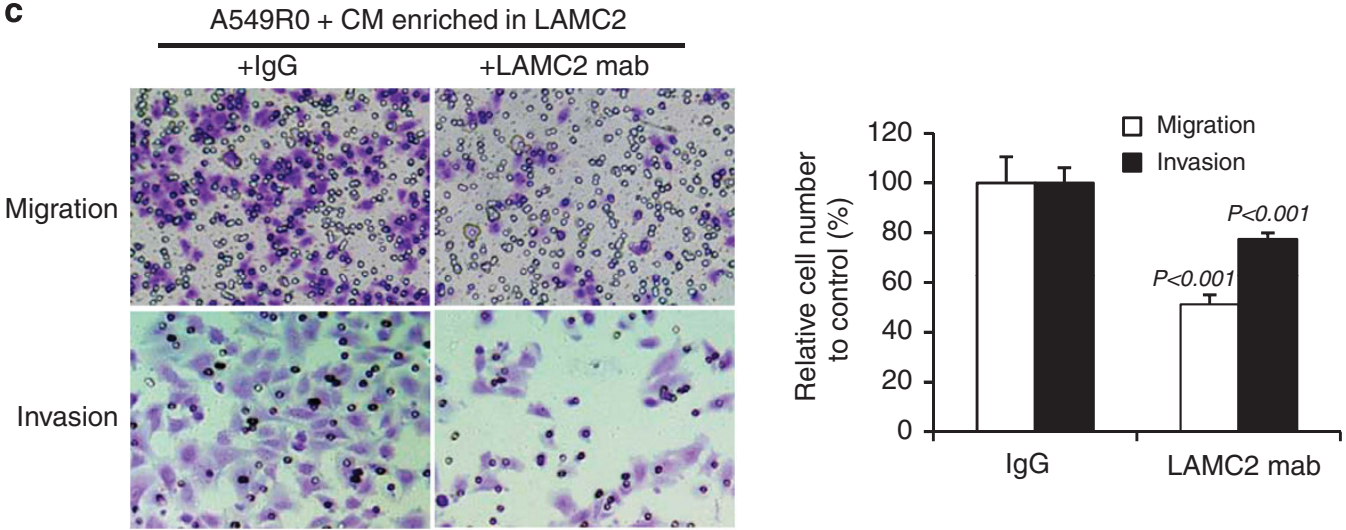

Figure 3 Conditioned medium containing secreted LAMC2 enhances cell migration and invasion, which can be blocked by LAMC2-blocking antibody. (a) Immunoblot analysis using the concentrated conditioned medium from LAMC2-transfected and -knockdown cells identified secreted unprocessed (140 kDa) and processed (100 kDa) LAMC2. Ponceau-S staining of the membrane is shown as protein loading controls of the conditioned medium. (b) Migration and invasion assay upon addition of conditioned medium from shLAMC2- and shMock-transfected cells to PC9-shLAMC2. Student's $t$-test was performed. Data are presented as mean \pm S.E.M. of triplicate experiments. (c) Migration and invasion assay upon addition of mixture of LAMC2-blocking antibody and LAMC2-containing conditioned medium from A549R0-LAMC2 cells, to A549R0-Mock cells. mAb was the blocking monoclonal antibody and immunoglobulin $\mathrm{G}(\mathrm{IgG})$ was used as the control. Student's $t$-test was performed. Data are presented as mean \pm S.E.M. of triplicate experiments

attenuated migration and invasion $(P<0.05$; Figure $5 \mathrm{~g})$, whereas ectopic Snail expression in H358-shLAMC2 $(P<0.05 ; \quad$ Figure $5 \mathrm{~h})$ and H322-shLAMC2 $(P<0.05$; Supplementary Figure S5A) cells increased migration and invasion, indicating that LAMC2-regulated migration and invasion is ZEB1- and/or Snail-dependent. ZEB1-shRNA knockdown attenuated the expression of vimentin (Figure $5 \mathrm{~g}$ ) and ectopic Snail expression augmented it (Figure 5h and Supplementary Figure S5A). Previous data indicate that modulation of the expression of the mesenchymal intermediate filament vimentin itself altered EMT migration and invasion. ${ }^{36,37}$ Stable ectopic expression of vimentin in H358-shLAMC2 (Figure 5i) and H322-shLAMC2 cells
(Supplementary Figure S5B) restored cellular migration and invasion (all $P$-values $<0.05$ ). To investigate the clinical relevance of LAMC2 expression in EMT induction, vimentin immunohistochemistry (IHC) was performed using tissue microarray (TMA) samples of stage I human lung ADCs (Yonsei Cancer Center (YCC) series). High LAMC2 expression was positively correlated with vimentin expression $(P=0.010 ; 26.0 \%$ in high LAMC2 group versus $9.9 \%$ in low LAMC2 group; data not shown). In addition, vimentin expression was also correlated with poor recurrence-free survival $(P=0.049$; Supplementary Figure S5C). Taken together, these data suggest that EMT may be one of the mechanisms by which LAMC2 enhances migration and invasion of lung ADC. 
a
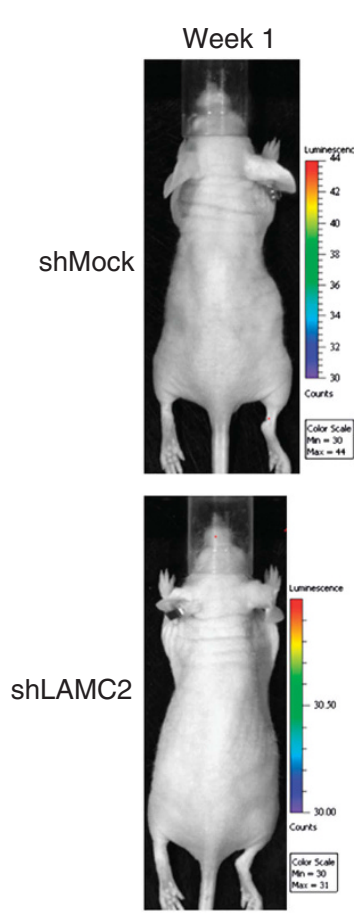

A549R4
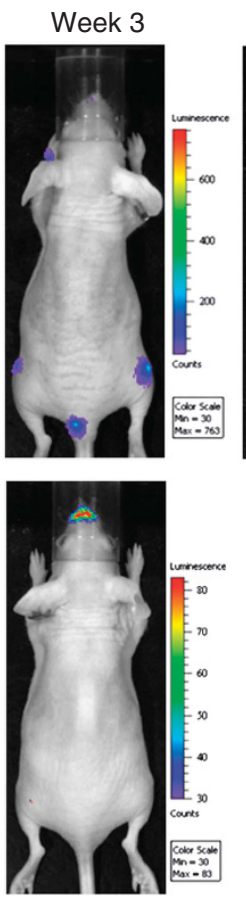

Week 6
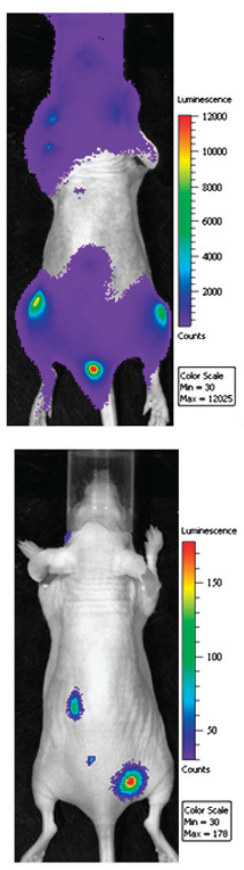

b
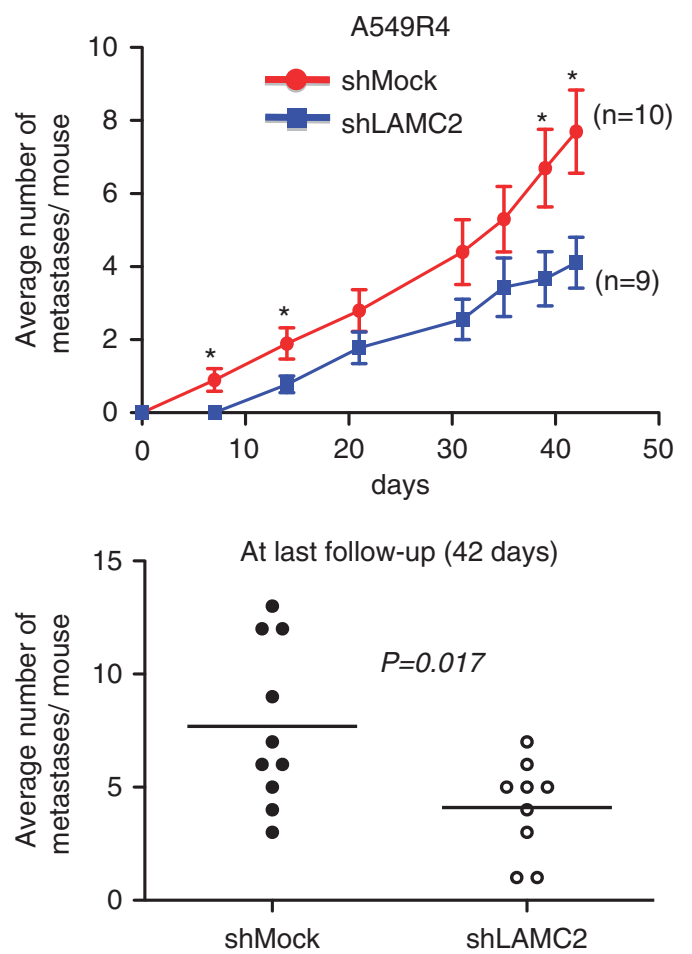

Figure 4 LAMC2 knockdown reduces metastatic capacity in a mouse metastasis model. (a) Representative images of serial noninvasive bioluminescence monitoring after intracardiac injection of the same number $\left(1 \times 10^{5}\right.$ cells) of luciferase-transfected A549R4-shLAMC2 and shMock cells. Mice were imaged dorsally for 3 min and then ventrally for another $3 \mathrm{~min}$. (b) Average number of metastases per mouse counted at different time points after intracardiac injection (upper panel) and comparison by Student's $t$-test at the last follow-up of 42 days (lower panel). Serial bioluminescent imaging was performed weekly for 4 weeks and then biweekly for the next 2 weeks. Metastasis was defined as the presence of bioluminescent signals at the same anatomic locations on three consecutive images. ${ }^{*} P<0.05 ; n=9$ mice for A549R4-shLAMC2 group and $n=10$ mice for shMock group. Data are presented as mean \pm S.E.M.

High expression of LAMC2 predicts poor prognosis in human lung ADC. To investigate the impact of LAMC2 expression on prognosis, three independent public mRNA microarray data sets of radically resected NSCLC patients (Supplementary Table S2) were analyzed. High LAMC2 expression was correlated with higher risk of recurrence and death in ADC patients, but not in the SCC patients (Figures $6 \mathrm{a}-\mathrm{c}$ ) by univariate analysis. Multivariate analysis, adjusted by stage, showed that LAMC2 expression remained a significant prognostic factor for patients with pStage I ADC (Supplementary Table S3).

We also evaluated LAMC2 expression by IHC on a TMA of 250 pStage I NSCLC samples from patients who underwent radical surgical resection (YCC series; Supplementary Table S2). The immunoreactivity of LAMC2 was mainly detected in the cytoplasm of tumor cells, and LAMC2 staining was positive at the epithelial-stromal interface, but not in the core of tumor nests (Figure 6d), in agreement with previous observations. ${ }^{38}$ When the cutoff for LAMC2 positivity was set at $30 \%$ (Figure $6 \mathrm{e}$ ), $33 \%$ of ADC and $25 \%$ of SCC cases were categorized as high LAMC2 groups. High LAMC2 was associated with a higher risk of recurrence $(P=0.027)$ and death $(P=0.012)$ in ADC but not in SCC (Figure 6f), although others, by stratifying LAMC2 expression based on the stromal types or LAMC2 distribution in tumors, showed that high LAMC2 expression in lung SCC with fibrous stroma composition or in invasive front of SCC was correlated with tumor aggressiveness. ${ }^{39,40}$ In line with the latter, overexpression of LAMC2 in $\mathrm{H} 1703$, a lung SCC cell line, augmented migration and invasion as compared with mock controls (Supplemental Figure 6a). Whether LAMC2 may have a similar role in lung SCC as in lung ADC remains to be investigated. Intriguingly, using the same criteria described by Takahashi et al., ${ }^{40}$ we stratified LAMC2 expression according to the stroma types in our TMA samples, and found that lung ADCs with fibrous stroma, although not associated with elevated LAMC2 expression $(P=0.19)$, were significantly correlated with worse recurrence-free survival (Supplementary Figure $6 \mathrm{~b} ; n=66$, $P=0.047)$. As only limited number of ADCs $(n=66)$ was evaluable for stroma-type stratification in our TMA samples, more samples are required to draw a definite conclusion. Prognostic significance of LAMC2 in ADC was maintained in multivariate analysis adjusted by stage (IA versus IB) (Supplementary Table S3). In summary, both microarray and IHC data indicated that LAMC2 expression is associated with poor prognosis in early-stage lung ADC, which lends strong support to our functional studies that LAMC2 may promote lung ADC metastasis.

\section{Discussion}

As tumor cells were intracardially injected into the blood stream in our mouse metastasis model, LAMC2 may enhance metastasis by facilitating extravasation and spreading to 

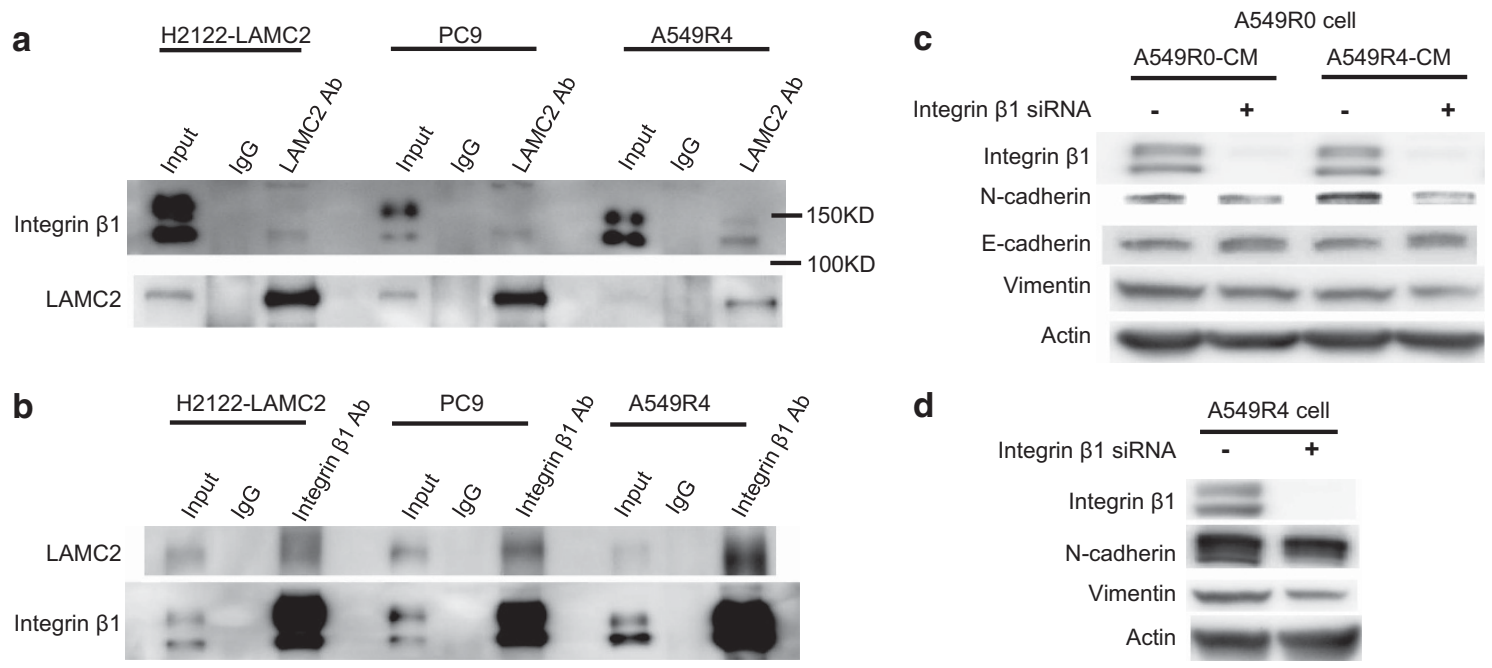

d

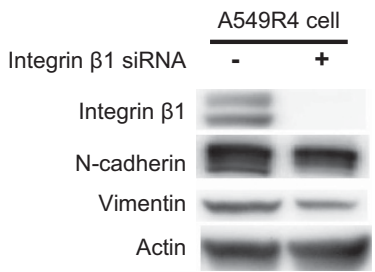

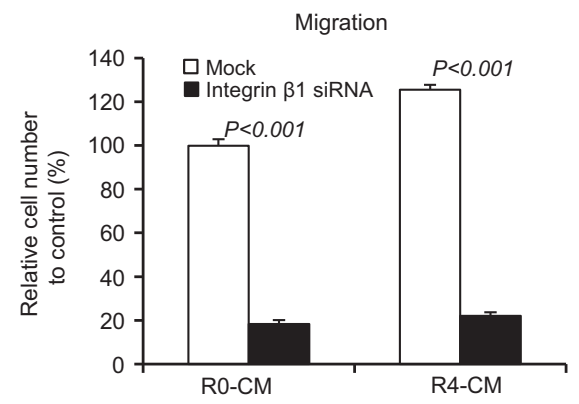

f

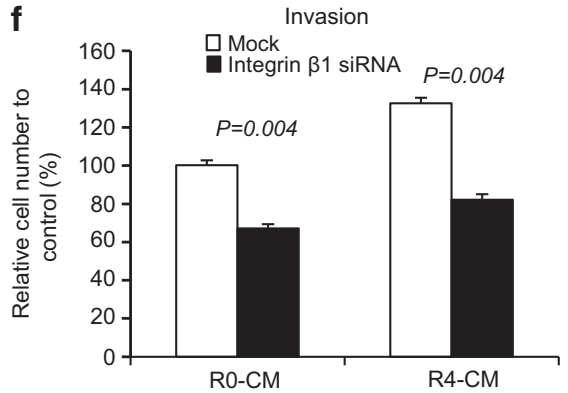

i
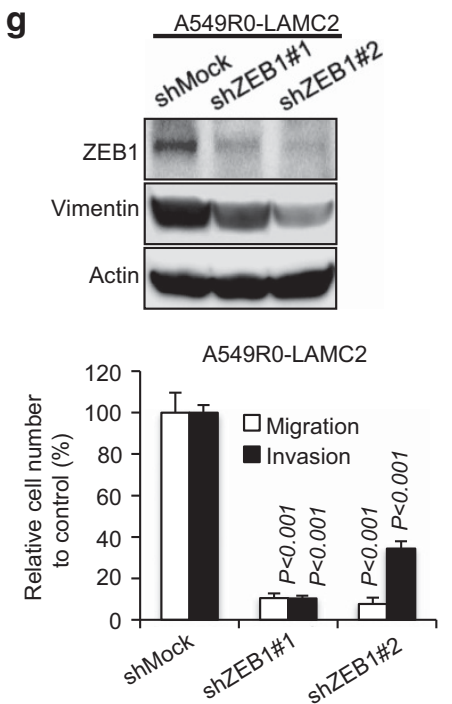

h
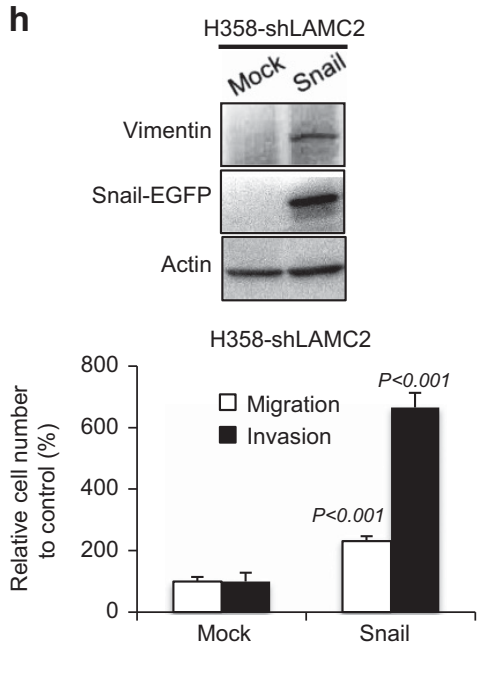

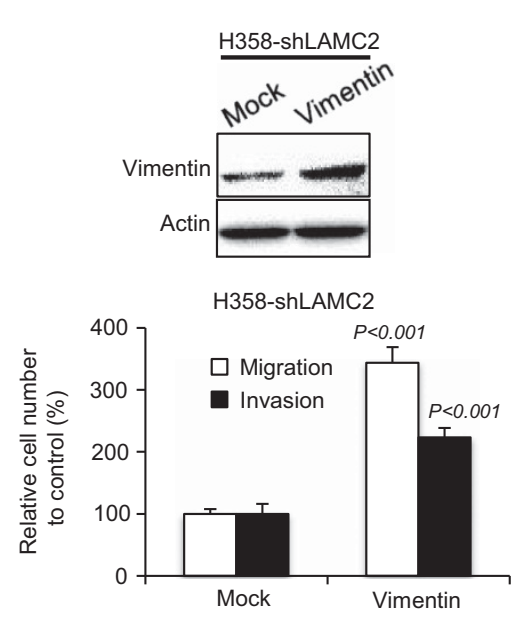

Figure 5 LAMC2 promotes migration and invasion via integrin $\beta 1$ - and/or ZEB1-dependent EMT. (a and $\mathbf{b}$ ) Co-immunoprecipitation of LAMC2 and integrin $\beta 1$ in H2122-LAMC2, PC9, and A549R4 cells. Cell lysates were immunoprecipitated with anti-LAMC2 (a) or -integrin $\beta 1$ antibodies (b). immunoglobulin G (lgG) was used as a negative control. The cell lysates and immunoprecipitates were analyzed by immunoblotting with the indicated antibodies. (c) A549R0 cells were pretreated with or without $25 \mathrm{nM}$ integrin $\beta 1$ siRNA for $48 \mathrm{~h}$. The cells were then incubated with A549R0 conditioned media (R0-CM) or A549R4 conditioned media (R4-CM) for $24 \mathrm{~h}$. Levels of integrin $\beta 1$, N-cadherin, E-cadherin, and vimentin were detected by immunoblot analysis. (d) Western blot analyses of integrin $\beta 1, \mathrm{~N}$-cadherin, and vimentin in A549R4 cells treated with or without $25 \mathrm{nM}$ integrin $\beta 1$ siRNA for $48 \mathrm{~h}$. Actin was used as the loading control. (e and f) Cell migration (e) and invasion (f) assays of A549R0 cells. A549R0 cells were pretreated with or without $25 \mathrm{nM}$ integrin $\beta 1$ siRNA for $48 \mathrm{~h}$, followed by incubation with the indicated conditioned media for $24 \mathrm{~h}$. Cells were then collected for migration and invasion assays. Data are presented as mean \pm S.E.M. of triplicate experiments. Knockdown of integrin $\beta 1$ significantly inhibits LAMC2-mediated migration $(P<0.001)$ and invasion $(P=0.004)$. (g) Knockdown of ZEB1 decreases migration and invasion of A549R0-LAMC2 cells. Student's t-test was performed to compare shMock cells and shZEB1 cells. Data are presented as mean \pm S.E.M. of triplicate experiments. (h) Ectopic expression of Snail restores migration and invasion in H358-shLAMC2 cells. Student's $t$-test was performed to compare Mock- and Snail-transfected cells. Data are presented as mean \pm S.E.M. of triplicate experiments. (i) Ectopic expression of vimentin restores migration and invasion in H358-shLAMC2 cells. Student's t-test was performed to compare Mock- and vimentin-transfected cells. Data are presented as mean \pm S.E.M. of triplicate experiments 


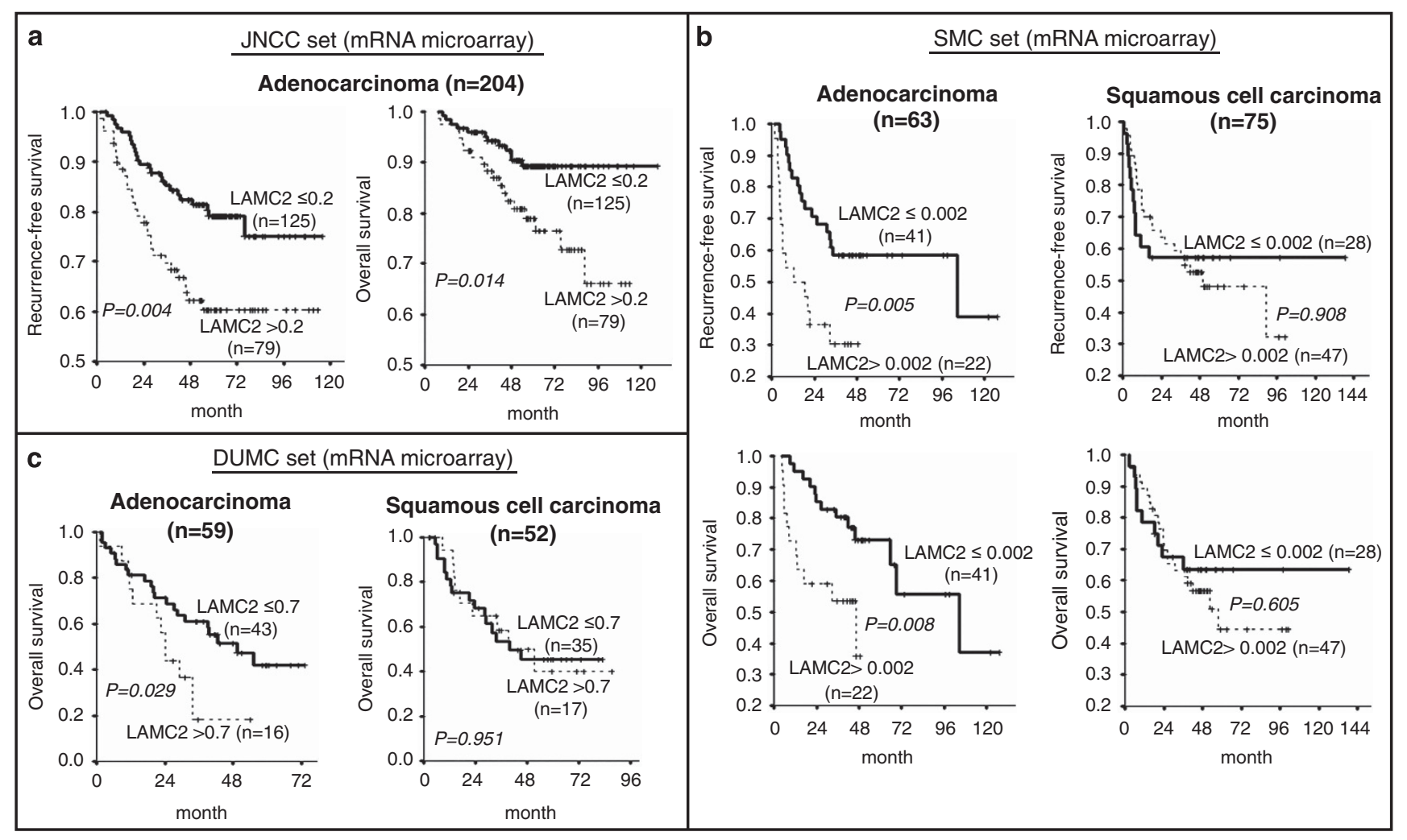

YCC set (Immunohistochemistry)

d

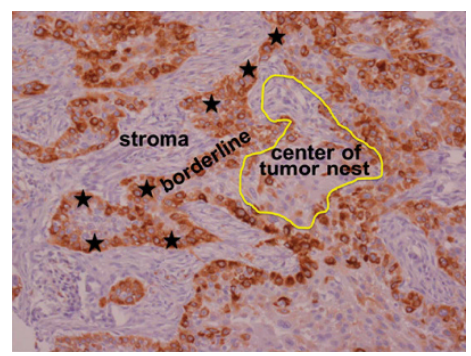

e

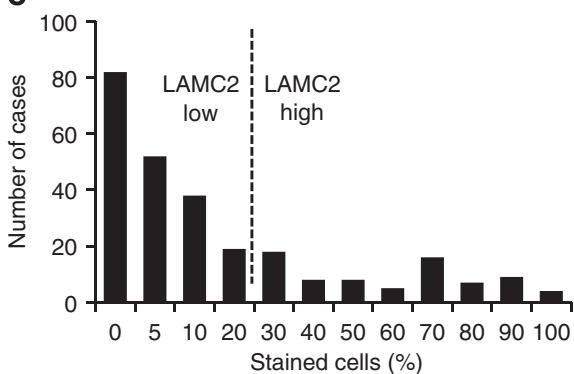

f Adenocarcinoma $(n=153)$
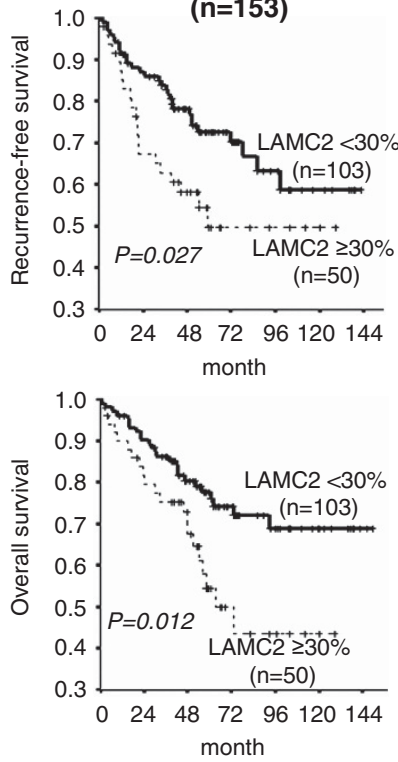

Squamous cell carcinoma
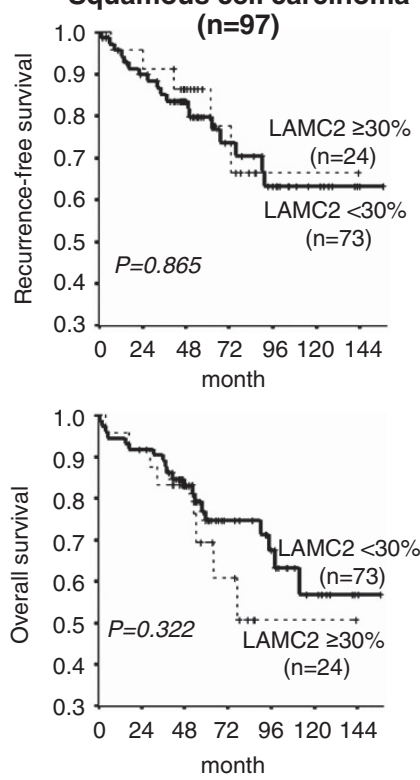

Figure 6 High expression of LAMC2 predicts poor prognosis in human lung ADC. (a-c) Kaplan-Meier survival curves according to relative LAMC2 mRNA expression from public mRNA microarray data sets: (a) JNCC (GSE31210), (b) SMC (GSE8894), and (c) DUMC (GSE3141). All patients included in these analyses were curatively resected for NSCLC and never received preoperative therapies. An optimal cutoff point for normalized intensity of LAMC2 mRNA was determined using minimum $P$-value approach in predicting recurrence-free or overall survival. Survival comparisons and $P$-values were determined by log-rank test. (d-f) Analysis of LAMC2 IHC on tissue microarray from patients with completely resected stage I NSCLC from YCC. (d) Pattern of strong LAMC2 staining at the epithelial-stromal interface (stars) of tumor nests, but no staining in the center of tumor nest (encircled in yellow). (e) Positivity for LAMC2 was assessed from 0 to $100 \%$ of stained cells by cytoplasmic or extracellular staining with any intensity. The cutoff of $30 \%$ was used for LAMC2 positivity as in previous reports using the same antibody. (f) Kaplan-Meier survival curves according to LAMC2 staining intensity. Survival comparisons and $P$-values were calculated by log-rank test 
distant target organs. Cells extend protrusions with lamellipodia or filopodia to initiate extracellular matrix (ECM) recognition and binding to ECM, which are the prerequisites for the onset of cell motility. ${ }^{41}$ The extended projected area of A549R0-LAMC2 cells in our biophysical assay may be the result of LAMC2-induced cell protrusion and contractile force, which are required for cell motility. Moreover LAMC2 IHC of lung ADC TMA showed that LAMC2 was predominant in tumor cells at the boundary between tumor and stroma, further supporting a role of LAMC2 in tumor cell spreading.

The clinical relevance of these findings was confirmed by a higher risk of recurrence or death in early-stage ADC patients with high tumor expression of LAMC2. Although adjuvant chemotherapy has been shown to increase survival by about $4 \%$ in stages II and III, its use is controversial in stage IB and associated with detrimental effect in stage IA. ${ }^{42}$ Strong prognostic factors in early stages of lung cancer are desperately needed, which could discriminate patients with a higher risk of tumor recurrence who might benefit from adjuvant chemotherapy. A plethora of putative prognostic markers have been identified, but most have not been independently validated. We and others ${ }^{5,6}$ demonstrated that LAMC2 protein expression correlated well with clinical outcome of stage I ADC patients, which was further supported by our functional studies in vitro and in vivo metastasis models. Moreover, it has been reported that serum LAMC2 exhibited diagnostic complementarity with CA19.9 in pancreatic ADC allowing earlier detection of primary or recurrent pancreatic cancer. ${ }^{8}$ Considering that secreted LAMC2 in the conditioned medium promotes lung cancer cell migration and invasion in our study, it is worth testing if serum or plasma LAMC2 may be used as a predictive biomarker of lung cancer metastasis, particularly in predicting the prognosis of early-stage lung ADC.

Although adjuvant chemotherapy has shown to increase survival in several solid tumors after radical resection (e.g. colon, breast, and lung), its nonspecificity and relatively high toxicity deserve careful consideration. In our study, we demonstrated that an anti-LAMC2 antibody inhibits migration and invasion of lung ADC cells in vitro. Antibody therapy targeting LAMC2 might help delay the metastatic progression by blocking migration and invasion steps of the metastatic cascades. This strategy could complement more specific antitumor therapies. Further studies of this strategy are warranted.

LAMC2 may increase metastatic potential through integrin $\beta 1-$, ZEB1-, and/or Snail-mediated EMT. We suggest that LAMC2 acts upstream of integrin $\beta 1$, ZEB1 and Snail, as manipulation of integrin $\beta 1$, ZEB1, and Snail expression alters LAMC2-induced migration, invasion, and EMT. Evidence suggests that FAK and SRC, through integrating intracellular signals, activate EMT regulators, ZEB1 and Snail. ${ }^{43}$ It is possible that the elevated LAMC2 in cancer cells may, through interaction with integrin $\beta 1$, hijack part of the focal adhesion complex including FAK/SRC kinase ${ }^{44}$ to induce EMT via ZEB1 and/or Snail.

In conclusion, our data show that LAMC2 enhances metastatic potential in lung ADC through engagement of EMT. LAMC2 is a strong prognostic marker in early stage ADC of the lung and can potentially be targeted to prevent metastasis.

\section{Materials and Methods}

Cell lines. Lung ADC cell lines (A549, NCl-H838, PC9, NCl-H2122, NCl-H358, and $\mathrm{NCl}-\mathrm{H} 322)$ were purchased from American Type Culture Collection (Manassas, VA, USA). All cancer cell lines were maintained in RPMI-1640, supplemented with $10 \%$ fetal bovine serum (FBS). Metastatic series of A549, A549R1, A549R2, A549R3, and A549R4, were established by repeated intracardiac injection of A549 in nude mice, as described below. Subconfluent A549 cells in culture were harvested, washed with PBS, resuspended in RPMI medium without phenol red, and injected into mice as described below.

Animal studies with intracardiac injection procedure. Animal experiments were performed in compliance with RARC guidelines of $\mathrm{NIH}$. Fiveto six-week-old female athymic NCr-nu/nu mice (NCl, Frederick, MD, USA) were anesthetized, laid on their back, and the cell suspension was injected into the left ventricle of the heart with a 27.5-gauge needle, through a transdiaphragmatic access. $^{45}$

In vivo selection of metastatic derivatives. Metastatic derivatives were obtained by repeated intracardiac injection of A549 cells and subsequent cultivation of metastatic tissues. A549R1, A549R2, and A549R3 cells were serially established by performing intracardiac injection of A549R0 $\left(5 \times 10^{5}\right.$ cells), A549R1 $\left(2.5 \times 10^{5}\right.$ cells), and A549R2 $\left(2.5 \times 10^{5}\right.$ cells), respectively. For each round, 10 mice were injected. To monitor end-organ metastasis of the metastatic derivatives, we generated a stable cell line expressing luciferase activity using A549R3 cells (A549R3-LUC). Bioluminescent imaging was performed in vivo after intracardiac injection of A549R3-LUC cells, as described in the respective section. Finally, A549R4-LUC-Brain, -Femur, and -Spine cells were established from the corresponding organ metastases. Detailed methods are described in the Supplementary section.

Gene expression profiling. To discover differentially expressed genes, we compared mRNA expression profiles between round 0 and round 3 cells using both A549 (our metastasis model system) and PC9 ADC cell lines, which is a publicly available data (GSE14107). ${ }^{21}$ We used the criteria of false discovery rate $<0.1$ and $\log 2$ fold change $>1.5$ or $<-1.5$. To evaluate the relationship between LAMC2 mRNA expression level and prognosis in NSCLC, we used three publicly available mRNA microarray data: the first cohort of 204 ADCs from Japanese National Cancer Center (JNCC set; HG-U133A Plus 2.0; GSE31210), ${ }^{46}$ the second cohort of a mix of 63 ADCs and 75 SCCs from the Samsung Medical Center (SMC set; HGU133A Plus 2.0; GSE8894), ${ }^{47}$ and the third cohort of 59 ADCs and 52 SCCs from Duke University Medical Center (DUMC set; HG-U133A Plus 2.0; GSE3141). ${ }^{48}$ Detailed methods were described in the Supplementary section.

IHC in human NSCLC specimens. The expression of LAMC2 and vimentin was determined by $\mathrm{IHC}$ from formalin-fixed, paraffin-embedded surgical specimens of 250 patients with NSCLC. All tumor specimens were obtained from a pathological stage I cohort, which underwent complete surgical resection between 1998 and 2007, without neoadjuvant treatment at YCC (Seoul, South Korea). Tumor staging was performed according to TNM staging revised in 2002 by American Joint Cancer Committee. ${ }^{49}$ Positivity for LAMC2 was assessed from 0 to $100 \%$ of stained cells by cytoplasmic staining with any intensity. The cutoff of $30 \%$ was used for LAMC2 positivity as in previous reports with the same antibody. ${ }^{11,14,50}$ Vimentin was considered to be positive if $\geq 1 \%$ of cancer cells were stained in the cytoplasm as reported previously. ${ }^{51,52}$ Detailed methods are described in the Supplementary section.

Fourier transform traction microscopy. Migrating cells exert traction forces upon their surrounding. We measured traction forces of ADC cell lines expressing different levels of LAMC2 using Fourier transform traction microscopy as described previously. ${ }^{53,54}$ Here, the computed traction field was used to obtain net contractile moment, which is a scalar measure of the cell's contractile strength. ${ }^{54}$ Net contractile moment is expressed in units of pico-Newton meters ( $\mathrm{pNm}$ ). Detailed methods are described in the Supplementary section. 
Conditioned medium and antibody blocking assay. When cells became confluent, RPMI-1640 medium containing 10\% FBS was replaced with fresh serum-free medium. After $24 \mathrm{~h}$ the conditioned medium was collected and concentrated using Amicon Ultra-Centrifugal filter (Millipore, Billerica, MA, USA) with molecular weight cutoff of $10 \mathrm{kDa}$ at $3800 \mathrm{~g}$ at $4^{\circ} \mathrm{C}$ until $500 \mu \mathrm{l}$ left on the top of filter $(\sim 20 \mathrm{~min})$. For LAMC2-blocking assay, A549R0 cells $\left(8 \times 10^{5}\right.$ and $4 \times 10^{5}$ cells for migration and invasion, respectively) were suspended in conditioned medium supplemented with $40 \mu \mathrm{g} / \mathrm{ml}$ mouse monoclonal LAMC2 antibody D4B5 (Millipore) as a blocking antibody or mouse IgG antibody as control and were plated in the upper chamber of the transwell plate. Detailed methods were described in the Supplementary section.

In vivo metastasis assay using intracardiac injection and bioluminescent imaging. The same number $\left(1 \times 10^{5}\right.$ cells) of A549R4LUC-shLAMC2 cells (9 mice) and A549R4-LUC-shMock cells (10 mice) in $100 \mu \mathrm{l}$ volume were injected into the left ventricle of the mouse. Serial bioluminescent imaging was performed weekly for four weeks and then biweekly for the next two weeks. Metastasis was defined as the presence of bioluminescent signals at the same anatomic locations on 3 consecutive images weekly or biweekly. Detailed methods are described in the Supplementary section.

\section{Conflict of Interest}

The authors declare no conflict of interests.

Acknowledgements. We thank Dr. Jhingook Kim for providing the GSE8894 data, Dr. Miyazaki for pBOS-CITE-Neo- 22 vector, Dr. Lynn Young for help with expression array data analysis, Yongzhen Qian for help with intracardiac injection, and Dr. Joon-Yong Chung for help with IHC. This study was supported by $\mathrm{NIH}$ intramural program and by NIH P30 CA51008 grant. SS An was funded by the $\mathrm{NIH}$ P50CA103175, U54CA141868 and HL107361 grants.

1. Siegel R, Naishadham D, Jemal A. Cancer statistics, 2013. Cancer J Clin 2013; 63: 11-30. 2. Herbst RS, Heymach JV, Lippman SM. Lung cancer. N Engl J Med 2008; 359: 1367-1380.

3. Valastyan S, Weinberg RA. Tumor metastasis: molecular insights and evolving paradigms. Cell 2011; 147: 275-292.

4. Colognato H, Yurchenco PD. Form and function: the laminin family of heterotrimers. Dev Dyn 2000; 218: 213-234

5. Moriya Y, Niki T, Yamada T, Matsuno Y, Kondo H, Hirohashi S. Increased expression of laminin-5 and its prognostic significance in lung adenocarcinomas of small size. An immunohistochemical analysis of 102 cases. Cancer 2001; 91: 1129-1141.

6. Kagesato $\mathrm{Y}$, Mizushima $\mathrm{H}$, Koshikawa N, Kitamura $\mathrm{H}$, Hayashi $\mathrm{H}$, Ogawa $\mathrm{N}$ et al. Sole expression of laminin gamma 2 chain in invading tumor cells and its association with stromal fibrosis in lung adenocarcinomas. Jpn J Cancer Res 2001; 92: 184-192.

7. Shou JZ, Hu N, Takikita M, Roth MJ, Johnson LL, Giffen C et al. Overexpression of CDC25B and LAMC2 mRNA and protein in esophageal squamous cell carcinomas and premalignan lesions in subjects from a high-risk population in China. Cancer Epidemiol Biomarkers Prev 2008; 17: 1424-1435.

8. Kosanam H, Prassas I, Chrystoja CC, Soleas I, Chan A, Dimitromanolakis A et al. Laminin, gamma 2 (LAMC2): a promising new putative pancreatic cancer biomarker identified by proteomic analysis of pancreatic adenocarcinoma tissues. Mol Cell Proteom 2013; 12 2820-2832.

9. Koshikawa N, Moriyama K, Takamura H, Mizushima H, Nagashima Y, Yanoma S et al. Overexpression of laminin gamma2 chain monomer in invading gastric carcinoma cells. Cancer Res 1999; 59: 5596-5601.

10. Hamasaki H, Koga K, Aoki M, Hamasaki M, Koshikawa N, Seiki M et al. Expression of laminin 5-gamma2 chain in cutaneous squamous cell carcinoma and its role in tumour invasion. Br J Cancer 2011; 105: 824-832.

11. Yamamoto H, Itoh F, Iku S, Hosokawa M, Imai K. Expression of the gamma(2) chain of laminin-5 at the invasive front is associated with recurrence and poor prognosis in human esophageal squamous cell carcinoma. Clin Cancer Res 2001; 7: 896-900.

12. Ono $Y$, Nakanishi $Y$, Ino $Y$, Niki T, Yamada T, Yoshimura $\mathrm{K}$ et al. Clinocopathologic significance of laminin-5 gamma2 chain expression in squamous cell carcinoma of the tongue: immunohistochemical analysis of 67 lesions. Cancer 1999; 85: 2315-2321.

13. Takahashi S, Hasebe T, Oda T, Sasaki S, Kinoshita T, Konishi M et al. Cytoplasmic expression of laminin gamma2 chain correlates with postoperative hepatic metastasis and poor prognosis in patients with pancreatic ductal adenocarcinoma. Cancer 2002; 94 : 1894-1901.

14. Smith SC, Nicholson B, Nitz M, Frierson Jr HF, Smolkin M, Hampton G et al. Profiling bladder cancer organ site-specific metastasis identifies LAMC2 as a novel biomarker of hematogenous dissemination. Am J Pathol 2009; 174: 371-379.
15. Thiery JP, Acloque $H$, Huang RY, Nieto MA. Epithelial-mesenchymal transitions in development and disease. Cell 2009; 139: 871-890.

16. Zhang Y, Yan W, Chen X. Mutant p53 disrupts MCF-10A cell polarity in three-dimensional culture via epithelial-to-mesenchymal transitions. J Biol Chem 2011; 286: 16218-16228.

17. Ke AW, Shi GM, Zhou J, Huang XY, Shi YH, Ding ZB et al. CD151 amplifies signaling by integrin alpha6beta1 to PI3K and induces the epithelial-mesenchymal transition in HCC cells. Gastroenterology 2011; 140: 1629-1641 e1615.

18. Aokage K, Ishii G, Ohtaki Y, Yamaguchi Y, Hishida T, Yoshida J et al. Dynamic molecular changes associated with epithelial-mesenchymal transition and subsequent mesenchymalepithelial transition in the early phase of metastatic tumor formation. Int J Cancer 2011; 128: 1585-1595.

19. Sanchez-Tillo E, de Barrios O, Siles L, Cuatrecasas M, Castells A, Postigo A. beta-catenin/ TCF4 complex induces the epithelial-to-mesenchymal transition (EMT)-activator ZEB1 to regulate tumor invasiveness. Proc Natl Acad Sci USA 2011; 108: 19204-19209.

20. Hlubek F, Jung A, Kotzor N, Kirchner T, Brabletz T. Expression of the invasion factor laminin gamma2 in colorectal carcinomas is regulated by beta-catenin. Cancer Res 2001; 61: 8089-8093.

21. Nguyen DX, Chiang AC, Zhang XH, Kim JY, Kris MG, Ladanyi M et al. WNT/TCF signaling through LEF1 and HOXB9 mediates lung adenocarcinoma metastasis. Cell 2009; 138: $51-62$

22. Liu L, Greger J, Shi H, Liu Y, Greshock J, Annan R et al. Novel mechanism of lapatinib resistance in HER2-positive breast tumor cells: activation of AXL. Cancer Res 2009; 69: 6871-6878.

23. Zhang Z, Lee JC, Lin L, Olivas V, Au V, LaFramboise T et al. Activation of the AXL kinase causes resistance to EGFR-targeted therapy in lung cancer. Nat Genet 2012; 44: 852-860.

24. Li Y, Ye X, Tan C, Hongo JA, Zha J, Liu J et al. Axl as a potential therapeutic target in cancer: role of Axl in tumor growth, metastasis and angiogenesis. Oncogene 2009; 28: 3442-3455.

25. Gjerdrum C, Tiron C, Hoiby T, Stefansson I, Haugen H, Sandal T et al. Axl is an essential epithelial-to-mesenchymal transition-induced regulator of breast cancer metastasis and patient survival. Proc Natl Acad Sci USA 2010; 107: 1124-1129.

26. Dembo M, Wang YL. Stresses at the cell-to-substrate interface during locomotion of fibroblasts. Biophys J 1999; 76: 2307-2316.

27. Harris AK, Wild P, Stopak D. Silicone rubber substrata: a new wrinkle in the study of cell locomotion. Science 1980; 208: 177-179.

28. Mierke CT, Rosel D, Fabry B, Brabek J. Contractile forces in tumor cell migration. Eur J Cell Biol 2008; 87: 669-676.

29. Wyckoff JB, Pinner SE, Gschmeissner S, Condeelis JS, Sahai E. ROCK- and myosindependent matrix deformation enables protease-independent tumor-cell invasion in vivo. Curr Biol 2006; 16: 1515-1523.

30. Miyazaki K, Kikkawa Y, Nakamura A, Yasumitsu H, Umeda M. A large cell-adhesive scatter factor secreted by human gastric carcinoma cells. Proc Natl Acad Sci USA 1993; 90: 11767-11771.

31. Tsuji T, Kawada Y, Kai-Murozono M, Komatsu S, Han SA, Takeuchi K et al. Regulation of melanoma cell migration and invasion by laminin-5 and alpha3beta1 integrin (VLA-3). Clin Exp Metast 2002; 19: 127-134.

32. Carpenter PM, Dao AV, Arain ZS, Chang MK, Nguyen HP, Arain S et al. Motility induction in breast carcinoma by mammary epithelial laminin 332 (laminin 5). Mol Cancer Res 2009; 7 : $462-475$

33. Matsui C, Wang CK, Nelson CF, Bauer EA, Hoeffler WK. The assembly of laminin-5 subunits. J Biol Chem 1995; 270: 23496-23503.

34. Decline F, Rousselle P. Keratinocyte migration requires alpha2beta1 integrin-mediated interaction with the laminin 5 gamma2 chain. J Cell Sci 2001; 114: 811-823.

35. Brockbank EC, Bridges J, Marshall CJ, Sahai E. Integrin beta1 is required for the invasive behaviour but not proliferation of squamous cell carcinoma cells in vivo. Br J Cancer 2005; 92. 102-112.

36. Vasko V, Espinosa AV, Scouten W, He H, Auer H, Liyanarachchi S et al. Gene expression and functional evidence of epithelial-to-mesenchymal transition in papillary thyroid carcinoma invasion. Proc Natl Acad Sci USA 2007; 104: 2803-2808.

37. Lahat G, Zhu QS, Huang KL, Wang S, Bolshakov S, Liu J et al. Vimentin is a novel anti-cancer therapeutic target; insights from in vitro and in vivo mice xenograft studies. PLoS One 2010; 5: e10105.

38. Maatta M, Soini Y, Paakko P, Salo S, Tryggvason K, Autio-Harmainen H. Expression of the laminin gamma2 chain in different histological types of lung carcinoma. A study by immunohistochemistry and in situ hybridization. J Pathol 1999; 188: 361-368.

39. Masuda R, Kijima H, Imamura N, Aruga N, Nakazato K, Oiwa K et al. Laminin-5gamma2 chain expression is associated with tumor cell invasiveness and prognosis of lung squamous cell carcinoma. Biomed Res (Tokyo, Japan) 2012; 33: 309-317.

40. Takahashi Y, Ishii G, Taira T, Fujii S, Yanagi S, Hishida T et al. Fibrous stroma is associated with poorer prognosis in lung squamous cell carcinoma patients. J Thorac Oncol 2011; 6: 1460-1467.

41. Friedl P, Wolf $K$. Tumour-cell invasion and migration: diversity and escape mechanisms. Nat Rev Cancer 2003; 3: 362-374.

42. Crino L, Weder W, van Meerbeeck J, Felip E. Early stage and locally advanced (non-metastatic) non-small-cell lung cancer: ESMO Clinical Practice Guidelines for diagnosis, treatment and follow-up. Ann Oncol 2010; 21(Suppl 5): v103-v115.

43. Bolos V, Gasent JM, Lopez-Tarruella S, Grande E. The dual kinase complex FAK-Src as a promising therapeutic target in cancer. Onco Targets Ther 2010; 3: 83-97. 
44. Marinkovich MP. Tumour microenvironment: laminin 332 in squamous-cell carcinoma. Nat Rev Cancer 2007; 7: 370-380.

45. Gril B, Palmieri D, Qian Y, Smart D, lleva L, Liewehr DJ et al. Pazopanib reveals a role for tumor cell B-Raf in the prevention of HER2+ breast cancer brain metastasis. Clin Cancer Res 2011; 17: 142-153.

46. Okayama H, Kohno T, Ishii $Y$, Shimada $Y$, Shiraishi $\mathrm{K}$, Iwakawa $\mathrm{R}$ et al. Identification of genes upregulated in ALK-positive and EGFR/KRAS/ALK-negative lung adenocarcinomas. Cancer Res 2011; 72: 100-111.

47. Lee ES, Son DS, Kim SH, Lee J, Jo J, Han J et al. Prediction of recurrence-free survival in postoperative non-small cell lung cancer patients by using an integrated model of clinical information and gene expression. Clin Cancer Res 2008; 14: 7397-7404.

48. Bild AH, Yao G, Chang JT, Wang Q, Potti A, Chasse D et al. Oncogenic pathway signatures in human cancers as a guide to targeted therapies. Nature 2006; 439: 353-357.

49. Greene FL, Balch CM, Fleming ID, April F, Haller DG. AJCC Cancer Staging Manual, 6 edn. New York, NY, USA: Springer, 2002.
50. Baba Y, lyama Kl, Hirashima K, Nagai Y, Yoshida N, Hayashi N et al. Laminin-332 promotes the invasion of oesophageal squamous cell carcinoma via PI3K activation. Br J Cancer 2008; 98: 974-980.

51. Yamashita N, Tokunaga E, Kitao H, Hisamatsu Y, Taketani K, Akiyoshi S et al. Vimentin as a poor prognostic factor for triple-negative breast cancer. J Cancer Res Clin Oncol 2013; 139: 739-746.

52. Zhang H, Liu J, Yue D, Gao L, Wang D, Zhang H et al. Clinical significance of E-cadherin, beta-catenin, vimentin and $\mathrm{S} 100 \mathrm{~A} 4$ expression in completely resected squamous cell lung carcinoma. J Clin Pathol 2013; 66: 937-945.

53. Garzon-Muvdi T, Schiapparelli P, ap Rhys C, Guerrero-Cazares H, Smith C, Kim DH et al. Regulation of brain tumor dispersal by NKCC1 through a novel role in focal adhesion regulation. PLOS Biol 2012; 10: e1001320.

54. Butler JP, Tolic-Norrelykke IM, Fabry B, Fredberg JJ. Traction fields, moments, and strain energy that cells exert on their surroundings. Am J Physiol Cell physiol 2002; 282: C595-C605.

Supplementary Information accompanies this paper on Cell Death and Differentiation website (http://www.nature.com/cdd) 